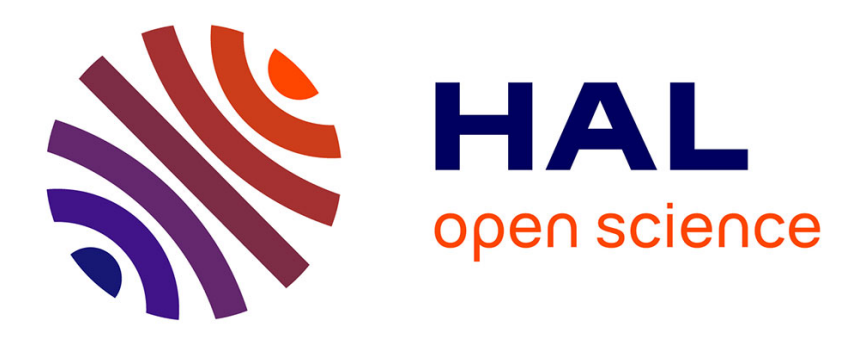

\title{
New explicit correlations for turbulent flow friction factor
}

Dejan Brkić

\section{To cite this version:}

Dejan Brkić. New explicit correlations for turbulent flow friction factor. Nuclear Engineering and Design, 2011, 241 (9), pp.4055-4059. 10.1016/j.nucengdes.2011.07.042 . hal-01586543

\section{HAL Id: hal-01586543 \\ https://hal.science/hal-01586543}

Submitted on 13 Sep 2017

HAL is a multi-disciplinary open access archive for the deposit and dissemination of scientific research documents, whether they are published or not. The documents may come from teaching and research institutions in France or abroad, or from public or private research centers.
L'archive ouverte pluridisciplinaire HAL, est destinée au dépôt et à la diffusion de documents scientifiques de niveau recherche, publiés ou non, émanant des établissements d'enseignement et de recherche français ou étrangers, des laboratoires publics ou privés. 


\section{Elsevier Editorial System(tm) for Nuclear Engineering and Design Manuscript Draft}

\section{Manuscript Number: NED-D-11-00090R1}

Title: New explicit correlations for turbulent flow friction factor

Article Type: Technical Note

Corresponding Author: Dr Dejan Brkic, PhD in Petroleum and Natural Gas Eng.

Corresponding Author's Institution:

First Author: Dejan Brkic, PhD in Petroleum and Natural Gas Eng.

Order of Authors: Dejan Brkic, PhD in Petroleum and Natural Gas Eng.

Abstract: Two new correlations of single-phase friction factor for turbulent pipe flow are shown in this paper. These two formulas are actually explicit approximations of iterative Colebrook's relation for calculation of flow friction factor. Calculated friction factor are valid for whole turbulent flow including hydraulically smooth and rough pipes with special attention on transient zone of turbulence between them. Hydraulically smooth regime of turbulence does not occur only in total absence of roughness of inner pipe surface, but also, four new relations for this theoretical regime are presented. Some recent formulas for turbulent flow friction calculation are also commented. 
I wish to thank reviewer to his or her valuable comments.

1. Abstract is now changed. Two new explicit approximations to the Colebrook approximation are shown. I did not see that Fang et al. favor their approximation for smooth pipes. In their paper is equally important approximation to the Colebrook equation. Also as I explained, the Colebrook equation is not only for "rough" pipes. It is for whole regime of turbulence which includes smooth and rough law and transient zone between them. Smooth law is not only valuable in absence of roughness and therefore equation of Fang et al. for smooth pipes has limited application as I explain in my text.

2. I do not use anymore Zigrang and Sylvester method from 1985 to estimate the complexity of approximations. But to be clear, Fang et al. approximation has few not simple power terms (1.1007, 1.1105 and 1.0712). These are not simple input parameters for hand calculators.

3. I examined approximation in 740 points in my paper "Review of explicit approximations to the Colebrook relation for flow friction". My results can be compared with results by Gregory and Fogarasi (1985) and Zigrang and Sylvester (1985). Both papers are in my reference list. Results by Yıldırım (2009) are different and I have comments in my paper on this. Gregory and Fogarasi (1985) and Zigrang and Sylvester (1985) are 25 years old research. My results with newly developed approximations can be compared with results from S. Genić, I. Arandjelović, P. Kolendić, M. Jarić, N. Budimir, V. Genić, A review of explicit approximations of Colebrook's equation, FME Transactions 39 (2011), 67-71. My analysis was done using MS Excel and I am preparing new research in MATLAB with much more points than 740 .

4. Moody diagram starts from 0 with laminar zone. Of course Colebrook's equation is only for turbulent zone. Turbulent zone is for Re $>2300$ or in the Moody chart for Re $>4000$. But laminar zone can exist up to $\mathrm{Re}=10^{4}$. To avoid any misunderstandings, my charts are for $\mathrm{Re}>10^{4}$. For example, from figure 1, for Fang et al. (2011) equation, it can be seen that relative error is up to $0.62 \%$ for $\mathrm{Re}>10^{4}$ (or about $0.73 \%$ for $\mathrm{Re}=3000$ ). I do not claim anymore that my analysis covers the entire Re range of the Moody diagram. I do not have deeper comments on Haaland or Barr approximation.

5. Colebrook paper is from Vol. 11, Issue 4 which was published in February 1939. Note that previous Issue 3 is in Vol. 10 which was published in January 1939. Issue 2 in Vol. 10 is the last from 1938. It is not usual practice, but this was in Journal of the ICE (Vol. 10 with issues 1 and 2 in 1938, Vol. 10 with issue 3 in 1939, Vol. 11 with issues 4, 5 and 6 in 1939, Vol. 12 with issue 7 and 8 in 1939)

6. My text is now with no informal expression. I hope that my English expression is now improved. 


\section{New explicit correlations for turbulent flow friction factor}

Dejan Brkić, Ph.D., Petroleum and Natural Gas Engineer, Strumička 88, 11050 Beograd, Serbia Tel. +381642543668, e-mail: dejanrgf@ tesla.rcub.bg.ac.rs

Abstract: Two new correlations of single-phase friction factor for turbulent pipe flow are shown in this paper. These two formulas are actually explicit approximations of iterative Colebrook's relation for calculation of flow friction factor. Calculated friction factor are valid for whole turbulent flow including hydraulically smooth and rough pipes with special attention on transient zone of turbulence between them. Hydraulically smooth regime of turbulence does not occur only in total absence of roughness of inner pipe surface, but also, four new relations for this theoretical regime are presented. Some recent formulas for turbulent flow friction calculation are also commented.

Nomenclature:

$\lambda$-Darcy, Darcy-Weisbach or Moody friction factor (dimensionless),

Re-Reynolds number (dimensionless)

$\varepsilon / \mathrm{D}$-Relative roughness of inner pipe surface (dimensionless) 


\section{Introduction}

Standard Colebrook's equation (1) is implicit in flow friction factor.

$$
\frac{1}{\sqrt{\lambda}}=-2 \cdot \log _{10}\left(\frac{2.51}{\operatorname{Re} \cdot \sqrt{\lambda}}+\frac{\varepsilon}{3.71 \cdot D}\right)
$$

Turbulent part of the famous Moody chart was drawn using Colebrook's results (Colebrook, 1939; Moody, 1944). Colebrook's formula can be used for whole turbulent regime including the smooth and the rough zone of turbulence and also for the transient zone between them.

Colebrook's formula has two parts which presents "smooth" and "rough" portion of turbulence. Only “smooth" part presented by Prandtl's formula (2) is implicit in friction factor.

$$
\frac{1}{\sqrt{\lambda}}=-2 \cdot \log _{10}\left(\frac{2.51}{\operatorname{Re} \cdot \sqrt{\lambda}}\right)=2 \cdot \log _{10}(\operatorname{Re} \cdot \sqrt{\lambda})-0.8
$$

"Rough" part in Colebrook's formula is presented by von Karman's formula (3) which is not implicitly given.

$$
\frac{1}{\sqrt{\lambda}}=-2 \cdot \log _{10}\left(\frac{\varepsilon}{3.71 \cdot D}\right)=-1.14-2 \cdot \log _{10}\left(\frac{\varepsilon}{D}\right)
$$

Prandtl's and von Karman's formula are also known as NPK (Nikuradse-Pandtl-von Karman) formulas.

Using logarithmic rules, one can found that Colebrook's formula is incorrect because $\log (\mathrm{A})+\log (\mathrm{B}) \neq \log (\mathrm{A}+\mathrm{B})$. But Colebrook's equation solves not problem from mathematics, but from hydraulics. Colebrook's formula is empirical and make fine transitional curve between smooth and rough turbulent law. NPK equations used separately for smooth law (Prandtl's 
equation) and for rough law (von Karman's equation) do not make such transitional curve. NPK equations represent only extremes of Colebrook formula. This is because the relative roughness of inner pipe surface $(\varepsilon / D)$ is not only physical characteristic of pipe surface. It also depends on thickness of laminar boundary layer which occurs near pipe wall during the turbulent flow of fluid. So one extreme of turbulence is smooth flow in total absence of roughness $(\varepsilon / D=0)$ covered by Prandtl's equation while other extreme is rough flow where boundary layer does not exist $(\varepsilon / D \rightarrow \max$ for observed inner pipe surface) which is covered by von Karman's equation. Colebrook's equation includes not only these two extremes presented by NPK equations but also smooth law where relative roughness is very small $(\varepsilon / D \rightarrow 0)$ with significant laminar boundary layer and also rest of turbulent regime where relative roughness smoothly increases to its physical maximum while thickness of laminar boundary layer decreases.

The Colebrook equation is also known under the Colebrook-White name, but this equation should be quoted in a correct way from source Colebrook (1939). Although, White was not actually a co-author of the paper in which considered equation was presented, Colebrook made a special point of acknowledging important contribution of White to the development of the equation based on his previous joint work (Colebrook and White, 1937). Paper of Colebrook is from 1939 (as can be seen from doi: 10.1680/ijoti.1939.13150 of this paper) and not from 193839 as often erroneously cited (volume 11 has only issues 4, 5 and 6 all from 1939).

Colebrook's formula can be solved in iterative procedure since it contains implicitly given flow friction factor. Also, numerous explicit approximations can be used to substitute implicit Colebrook's equation which cannot be solved for unknown flow friction factor with no 
approximate calculus (Moody, 1947; Wood, 1966; Eck, 1973; Churchill, 1973; Swamee and Jain, 1976; Jain, 1976; Churchill, 1977; Chen, 1979; Round, 1980; Barr, 1981; Zigrang and Sylvester, 1982; Haaland, 1983; Serghides, 1984; Manadilli, 1997; Romeo et al. 2002; Sonnad and Goudar, 2006; Buzzelli, 2008; Avci and Karagoz, 2009; Vatankhah and Kouchakzadeh, 2009; Papaevangelou et al., 2010; Brkić, 2011a,b; Fang et al. 2011; Ghanbari et al., 2011). Two novel explicit approximations to the Colebrook's formula will be shown in further text.

\section{Some recent explicit formulas for turbulent flow friction}

There are many different explicit formulas developed to substitute implicit Colebrook's relation. Most recent formula is by Fang et al. (2011). Fang et al. (2011) estimated very accurately maximal relative error up to $0.5 \%$ for their approximation of Colebrook's formula. From figure 1 , it can be seen that this error is slightly bigger, up to $0.62 \%$ for $\operatorname{Re}>10^{4}$ (or about $0.73 \%$ for $\operatorname{Re}=3000$ ). This is very accurate which means that their approximation is in first ten sorted by accuracy (Brkić, 2011c).

Figure 1. Distribution of estimated relative error of approximation by Fang et al. (2011) compared with iterative solution of implicit Colebrook equation

Also, approximations proposed by Romeo et al. (2002), Buzzelli (2008), more complex form of approximation by Serghides (1984), more complex form of approximation by Zigrang and Sylvester (1982) and approximation by Vatankhah and Kouchakzadeh (2009) will always give more accurate results than those calculated by approximations proposed by Fang et al. (2011) as shown in figure 2. On the other hand as shown in figure 3 , inconclusive conclusion of accuracy 
in general can be found by using of approximation by Barr (1981), simpler form of approximation by Serghides (1984), approximation by Chen (1979), Sonnad and Goudar (2006), Papaevangelou et al. (2010) and by using simpler form of approximations by Zigrang and Sylvester (1982), all versus approximation by Fang et al. (2011). Approximation proposed by Fang et al. (2011) will give better prediction of implicit Colebrook equation compared with other approximations from Brkić (2011c).

Figure 2. Approximation of Fang et al. (2011) compared with the most accurate approximations

Figure 3. Approximation of Fang et al. (2011) compared with moderate accurate approximations

Relative error of certain approximations to the Colebrook equation was also presented in Gregory and Fogarasi (1985) and Zigrang and Sylvester (1985). As noted by Fang et al. (2011), Yıldırım (2009) conducted comprehensive analysis of existing correlations for single-phase friction but he used Techdig 2.0 software which caused remarkable reading errors factor. Findings by Brkić (2011c) as well as findings by Fang et al. (2011) do not support Yıldırım's error estimations because he greatly overestimated errors and offered different accuracy-based rank order for the correlations evaluated than in Fang et al. (2011) or in Brkić (2011c). One can be always aware that Moody diagram was constructed using Colebrook's equation and not opposite (Colebrook, 1939; Moody, 1944). It is not acceptable to replace cause and its consequence such was done by reading of points from Moody diagram using Techdig 2.0 software. Ghanbari et al. (2011) also made their approximation of Colebrook's equation based on 
data which was obtained by digitizing the Moody's diagram. This approach produces approximation with error up to $3 \%$ as can be seen from figure 4 .

Figure 4. Distribution of estimated relative error of approximation by Ghanbari et al. (2011) compared with iterative solution of implicit Colebrook equation

Use of input data in model proposed by Ghanbari et al. (2011) obtained by iterative solution of Colebrook's equation instead of the data from Moody's diagram would almost certain produce more accurate approximation.

\section{New explicit approximations to the Colebrook's formula}

In some recent papers, few new explicit approximations of Prantdl's relation were shown (Fang et al., 2011; Li et al., 2011; Danish et al., 2011). As noted before, Prantdl's relation is actually Colebrook's equation in the case of total absence of relative roughness ( $(\mathrm{D} / \mathrm{D})$. Approximations to the Prandtl equation by Fang et al. (2011) and Li et al. (2011) are suitable for transformation in approximations to the Colebrook equation. Approximations to the Prandtl equation given in suitable form (with its smooth part " $x$ " transformed in explicitly given form) can be easily transformed in approximation to the Colebrook equation (4).

$$
\frac{1}{\sqrt{\lambda}}=-2 \cdot \log _{10}(x) \rightarrow \frac{1}{\sqrt{\lambda}}=-2 \cdot \log _{10}\left(x+\frac{\varepsilon}{3.71 \cdot D}\right)
$$

Using approximations to the Prandtl equation proposed in Fang et al. (2011), new approximation to the Colebrook equation can be obtained (5).

$$
\frac{1}{\sqrt{\lambda}}=-2 \cdot \log _{10}\left[\frac{150.39}{\operatorname{Re}^{0.98865}}-\frac{152.66}{\operatorname{Re}}+\frac{\varepsilon}{3.71 \cdot D}\right]
$$


After few simple transformations new approximation to the Colebrook equation (6) can be obtained from approximations to the Prandtl equation proposed in Li et al. (2011).

$$
\frac{1}{\sqrt{\lambda}}=-2 \cdot \log _{10}\left(\frac{1.25603}{\operatorname{Re} \cdot \sqrt{\frac{-0.0015702}{\ln (\mathrm{Re})}+\frac{0.3942031}{\ln ^{2}(\mathrm{Re})}+\frac{2.5341533}{\ln ^{3}(\mathrm{Re})}}}+\frac{\varepsilon}{3.71 \cdot D}\right)
$$

Distribution of relative error for both presented approximations (marked as new in figure 6) to the Colebrook equation can be seen in figure 5 .

Figure 5. Distribution of estimated relative error of two new approximations compared with iterative solution of implicit Colebrook equation

Presented equations with relative error up to $2 \%$ can be used to substitute implicit Colebrook's equation. This error is comparable with other available approximations as can be seen from figure 6.

Figure 6. Two new approximations compared with some other available approximations to the Colebrook equation

Both equations are presented in figure 6 are presented with one line "new" since they produce identical error. The Colebrook equation is empirical and therefore error of $2 \%$ can be neglected.

\section{New explicit approximations to the Prandtl's formula}


Hydraulically smooth regime of turbulence does not occur only in total absence of roughness of inner pipe surface (Brkić, 2011d), but also, four new relations for this theoretical regime are presented. As noted before, Colebrook's equation in total absence of relative roughness is actually Prandtl's equation, and vice versa. These four approximations to the Prandtl equation was developed using inverse procedure from previous section, i.e. from appropriate approximations to the Colebrook formula, "rough" part was simply removed (Table 1).

Table 1: Equations for hydraulically smooth regime developed for total absence of roughness (when $\varepsilon / D=0$ )

Approximations to the Prandtl equation (new 1-4) were developed using approximations to the Colebrook formula shown in Romeo et al. (2002), Zigrang and Sylvester (1982), Manadilli (1997), and Serghides (1984), respectively (new 1-4).

Comparison of presented approximations of Prandtl's relation is given in figure 7.

Figure 7. Accuracy of some approximations to the Prandtl equation

With relative error of up to $0.15 \%$ to the Prandl equation, all approximations from table 1 can be used instead of implicit form of Prandtl's equation (or Colebrook's when $\varepsilon / \mathrm{D}=0$ ).

\section{Conclusion}

Two new explicit approximations to the standard implicit Colebrook equation are shown. Their relative error over the entire practical domain of Reynolds number and relative roughness are up 
to $2 \%$. Since the Colebrook equation is empirical this is good results. In that way, main goal which is avoiding of iterative procedure is fulfilled. Also, there are many explicit approximations to the implicit Prandtl equation in literature. The Prandtl equation is actually the Colebrook equation in total absence of inner pipe roughness. In some cases, an explicit approximation to the Colebrook equation can be easily used to develop an explicit approximation to the Prandtl equation. Procedure for this is explained in text, and vice versa, using some of the explicit approximations to the Colebrook equation known from literature, for new explicit approximations to the Prandtl equation were developed. With relative error of no more than $0.15 \%$, these for equations are very accurate.

\section{References:}

Avci, A., Karagoz, I. 2009. A novel explicit equation for friction factor in smooth and rough pipes. J. Fluid. Eng. ASME 131(6), 061203 (1-4).

Barr, D.I.H. 1981. Solutions of the Colebrook-White function for resistance to uniform turbulent flow. Proc. Inst. Civil. Eng. 71(2), 529-536.

Brkić, D. 2011a. An explicit approximation of the Colebrook equation for fluid flow friction factor. Petrol. Sci. Tech. 29(15), 1596-1602.

Brkić, D. 2011b. W solutions of the CW equation for flow friction. Appl. Math. Lett. 24(8), 1379-1383.

Brkić, D. 2011c. Review of explicit approximations to the Colebrook relation for flow friction. J. Pet. Sci. Eng. 77(1), 34-48.

Brkić, D. 2011d. Gas distribution network hydraulic problem from practice, Petrol. Sci. Tech. 29(4), 366-377. 
Buzzelli, D. 2008. Calculating friction in one step. Mach. Des. 80(12), 54-55.

Chen, N.H. 1979. An explicit equation for friction factor in pipes. Ind. Eng. Chem. Fundam. 18(3), 296-297.

Churchill, S.W. 1973. Empirical expressions for the shear stress in turbulent flow in commercial pipe. AIChE J. 19(2), 375-376.

Churchill, S.W. 1977. Friction-factor equation spans all fluid flow regimes. Chem. Eng. 84(24), 91-92.

Colebrook, C.F. 1939. Turbulent flow in pipes with particular reference to the transition region between the smooth and rough pipe laws. J. Inst. Civil. Eng. (London) 11(4), 133-156.

Colebrook, C.F., White C.M. 1937. Experiments with fluid friction in roughened pipes. Proc. Roy. Soc. Ser. A Math. Phys. Sci. 161(906), 367-381.

Danish, M., Kumar, S., Kumar, S., 2011. Approximate explicit analytical expressions of friction factor for flow of Bingham fluids in smooth pipes using Adomian decomposition method.

Commun. Nonlinear. Sci. Numer. Simulat. 16(1), 239-251.

Eck, B. 1973. Technische Stromungslehre; Springer: New York.

Fang, X., Xu, Y., Zhou, Z. 2011. New correlations of single-phase friction factor for turbulent pipe flow and evaluation of existing single-phase friction factor correlations. Nucl. Eng. Des. 241(3), 897-902.

Ghanbari, A., Farshad, F.F., Rieke, H.H. 2011. Newly developed friction factor correlation for pipe flow and flow assurance. J. Chem. Eng. Mater. Sci. 2(6), 83-86.

Gregory, G.A., Fogarasi, M. 1985. Alternate to standard friction factor equation. Oil. Gas. J. 83(13), 125-127, 120. 
Haaland, S.E. 1983. Simple and explicit formulas for friction factor in turbulent pipe flow. J. Fluid. Eng. ASME 105(1), 89-90.

Jain, A.K. 1976. Accurate explicit equation for friction factor. J. Hydraul. Div. ASCE 102(HY5), 674-677.

Li, P., Seem, J.E., Li, Y., 2011. A new explicit equation for accurate friction factor calculation of smooth pipes. Int. J. Refrig. in press, doi.10.1016/j.ijrefrig.2011.03.018

Manadilli, G. 1997. Replace implicit equations with signomial functions. Chem. Eng. 104(8), $129-130$.

Moody, L.F. 1944. Friction factors for pipe flow. Trans. ASME 66(8), 671-684.

Moody, L.F. 1947. An approximate formula for pipe friction factors. Trans. ASME 69(12), 1005-1011.

Papaevangelou G, Evangelides C, Tzimopoulos C. 2010. A new explicit equation for the friction coefficient in the Darcy-Weisbach equation, Proceedings of the Tenth Conference on Protection and Restoration of the Environment: PRE10, July 6-9, 2010, Greece, Corfu, 166, pp. 1-7.

Romeo, E., Royo, C., Monzon, A. 2002. Improved explicit equation for estimation of the friction factor in rough and smooth pipes. Chem. Eng. J. 86(3), 369-374.

Round, G.F. 1980. An explicit approximation for the friction factor-Reynolds number relation for rough and smooth pipes. Can. J. Chem. Eng. 58(1), 122-123.

Serghides, T.K. 1984. Estimate friction factor accurately. Chem. Eng. 91(5), 63-64.

Sonnad, J.R., Goudar, C.T. 2006. Turbulent flow friction factor calculation using a mathematically exact alternative to the Colebrook-White equation. J. Hydraul. Eng. ASCE 132(8), 863-867. 
Swamee, P.K., Jain A.K. 1976. Explicit equations for pipe flow problems. J. Hydraul. Div. ASCE 102(HY5), 657-664.

Vatankhah, A.R., Kouchakzadeh, S. 2009. Discussion: Exact equations for pipe-flow problems, by P.K. Swamee and P.N. Rathie. J. Hydraul. Res. IAHR 47(7), 537-538.

Wood, D.J. 1966. An explicit friction factor relationship. Civil. Eng. 36(12), 60-61.

Y1ldırım, G. 2009. Computer-based analysis of explicit approximations to the implicit

Colebrook-White equation in turbulent flow friction factor calculation. Adv. Eng. Softw. 40(11), $1183-1190$.

Zigrang, D.J., Sylvester, N.D. 1982. Explicit approximations to the solution of Colebrook friction factor equation. AIChE J. 28(3), 514-515.

Zigrang, D.J., Sylvester, N.D. 1985. A review of explicit friction factor equations. J. Energ. Resour. ASME 107(2), 280-283.

Dejan Brkić (1975) received his PhD degree in petroleum and natural engineering from the University of Belgrade (Serbia) in 2010. His PhD research was supported from the Ministry of Science and Technological Development of Republic of Serbia during a scholarship program. He holds also MS degree in petroleum engineering (2002) and MS degree in treatment and transport of fluids (2005), both from the University of Belgrade. He has also postgraduate education in field of environmental protection. He published over 15 research papers in international journals. His research interest includes hydraulics and natural gas. Brkić is currently finishing MS degree studies in mechanical engineering at the University of Niš (Serbia). 
List of tables:

Table 1: Equations for hydraulically smooth regime developed for total absence of roughness (when $\varepsilon / \mathrm{D}=0$ ) 
List of figures:

Figure 1. Distribution of estimated relative error of approximation by Fang et al. (2011) compared with iterative solution of implicit Colebrook equation

Figure 2. Approximation of Fang et al. (2011) compared with the most accurate approximations Figure 3. Approximation of Fang et al. (2011) compared with moderate accurate approximations Figure 4. Distribution of estimated relative error of approximation by Ghanbari et al. (2011) compared with iterative solution of implicit Colebrook equation

Figure 5. Distribution of estimated relative error of two new approximations compared with iterative solution of implicit Colebrook equation

Figure 6. Two new approximations compared with some other available approximations to the Colebrook equation

Figure 7. Accuracy of some approximations to the Prandtl equation 
Table 1: Equations for hydraulically smooth regime developed for total absence of roughness (when $\varepsilon / D=0$ )

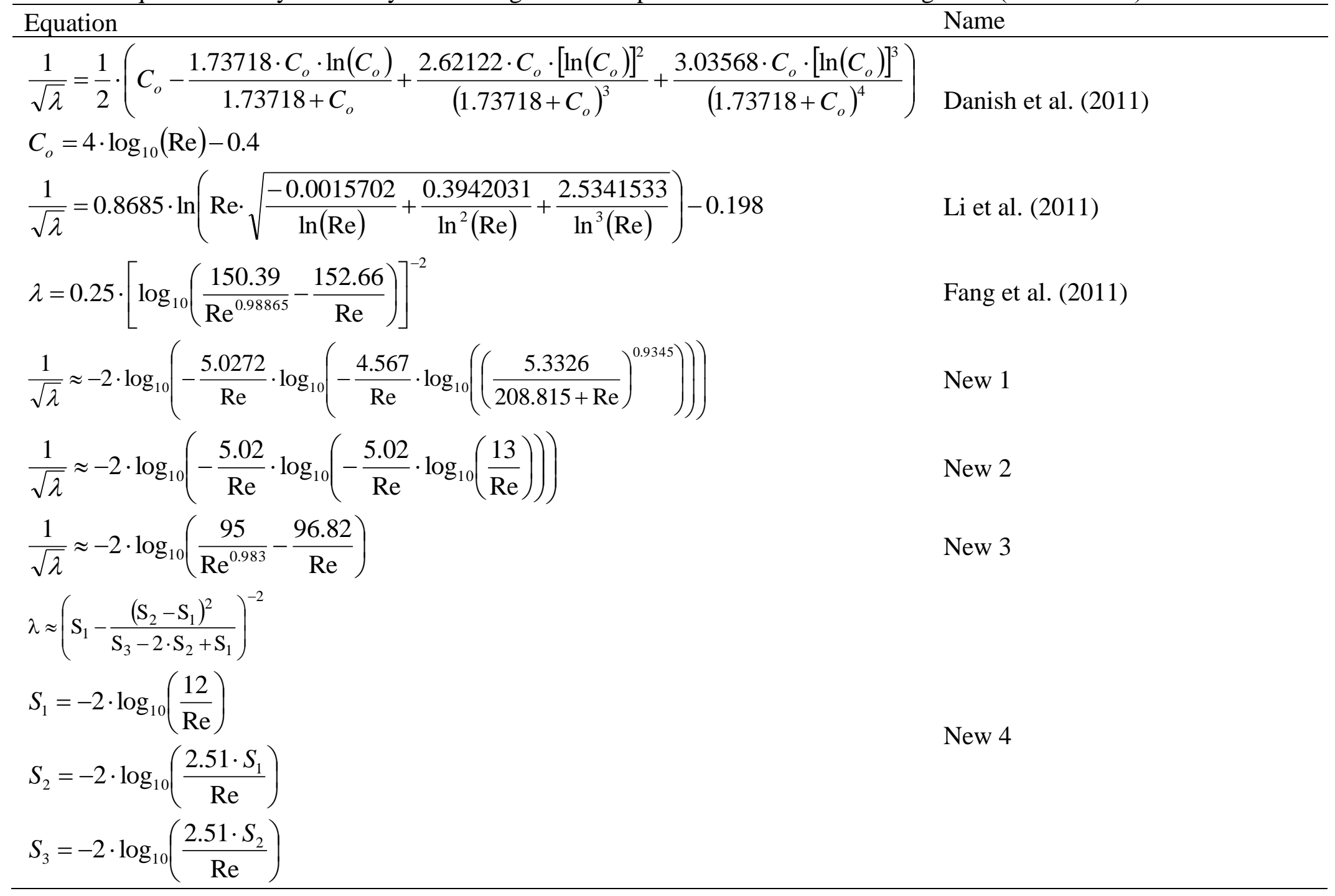


Fang et al. (2011):

$\lambda \approx 1.613 \cdot\left[\ln \left(0.234 \cdot(\varepsilon / D)^{1.1007}-60.525 / \operatorname{Re}^{1.1105}+56.291 / \operatorname{Re}^{1.0712}\right)\right]^{-2}$

Relative roughness: $\varepsilon / D$

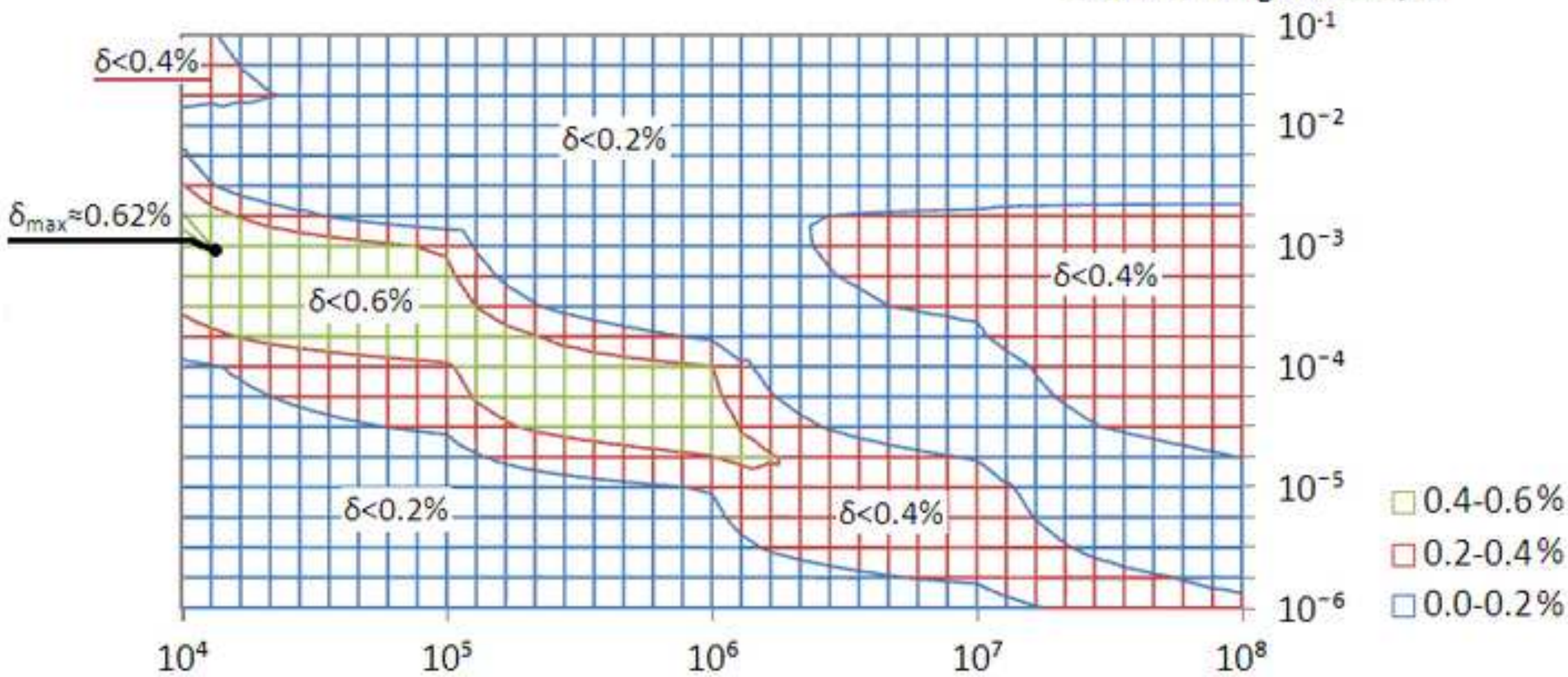

Reynolds number: $\operatorname{Re}$ 


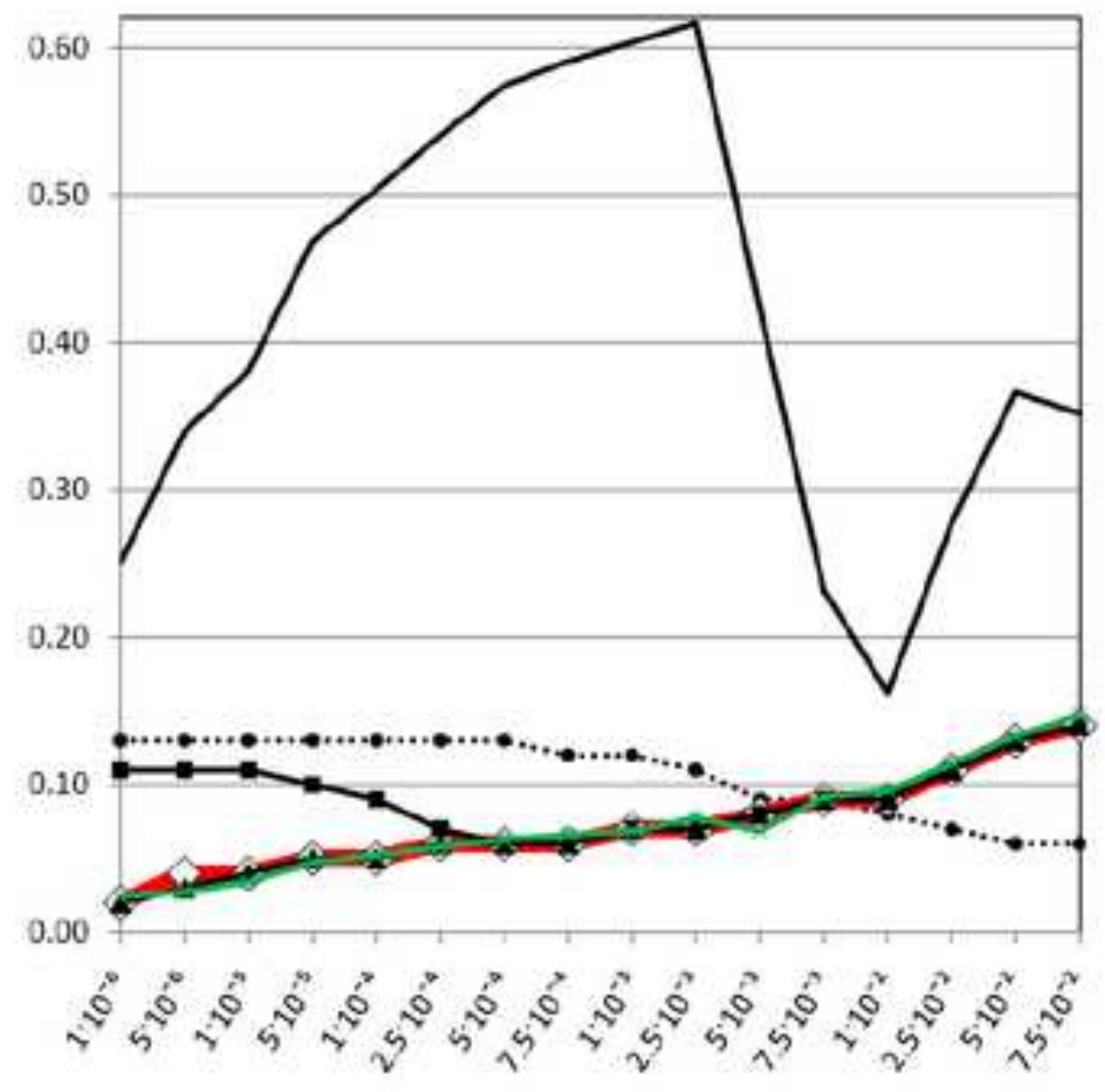

Relative roughness $(\varepsilon / 0)$
..... Romeo et al. (2002):

$\lambda=\left(-2 \cdot \log _{10}\left[(\varepsilon / D) / 3.7065-(5.0272 / \operatorname{Re}) \cdot \log _{10}[(\varepsilon / D) / 3.827\right.\right.$.

$\left.\left.\left.-(4.567 / \operatorname{Re})-\log _{10}\left[((\varepsilon / D) / 7.7918)^{0.9 n 4}+(5.3326 /(208.815+\operatorname{Re}))^{0.9345}\right]\right]\right]\right)^{-2}$

$\Rightarrow=$ Buzzelli (2008): $\lambda=\left(A \cdot\left[\left(A+2 \cdot \log _{10}(B / R e)\right) /(1+2.18 / B)\right]\right)^{-2}$ $A=[(0.774 \cdot \ln (\operatorname{Re})-1.41)] /\left[1+1.32 \cdot(\varepsilon / D)^{05}\right]$ $\mathrm{B}=\operatorname{Re} \cdot(\varepsilon / \mathrm{D}) / 3.7+2.51 \cdot \mathrm{A}$

$\longrightarrow$ Serghides $(1984): \lambda=\left(C_{1}-\left(C_{2}-C_{1}\right)^{2} /\left(C_{3}-2 \cdot C_{2}+C_{1}\right)\right)^{2}$

$$
\begin{aligned}
& C_{1}=-2 \cdot \log _{10}((\varepsilon / D) / 3.7+12 / R e) \\
& C_{2}=-2 \cdot \log _{10}\left((\varepsilon / D) / 3.7+\left(2.51 \cdot C_{1}\right) / R e\right) \\
& C_{3}=-2 \cdot \log _{10}\left((\varepsilon / D) / 3.7+\left(2.51 \cdot C_{2}\right) / R e\right)
\end{aligned}
$$

$\longrightarrow$ Zigrang and Sylvester (1982):

$\lambda \approx\left[-2 \cdot \log _{10}\left[(\varepsilon / D) / 3.7-5.02 / R e \cdot \log _{10}[(\varepsilon / D) / 3.7-\right.\right.$ $\left.\left.\left.-5.02 / \operatorname{Re} \cdot \log _{10}[(\varepsilon / D) / 3.7+13 / \operatorname{Re}]\right]\right]\right)^{2}$

-Vatankhah and Kouchakzadeh (2009):

$\lambda=\left(0.8686 \cdot \ln \left[0.4587 \cdot \operatorname{Re} /(S \cdot 0.28)^{\mathrm{S} /(\mathrm{S} \cdot 0.851]}\right]\right)^{2}$

$\$=0.124 \cdot \operatorname{Re} \cdot(\varepsilon / D)+\ln (0.4587 \cdot \operatorname{Re})$

Fang et al. (2011);

$\lambda=\left(1.613 \cdot \ln \left[0.234-(\varepsilon / D)^{1.1007} \cdot 60.525 / \operatorname{Re}^{1.1105}+56.291 / \operatorname{Re}^{1.0712}\right]\right)^{2}$ 


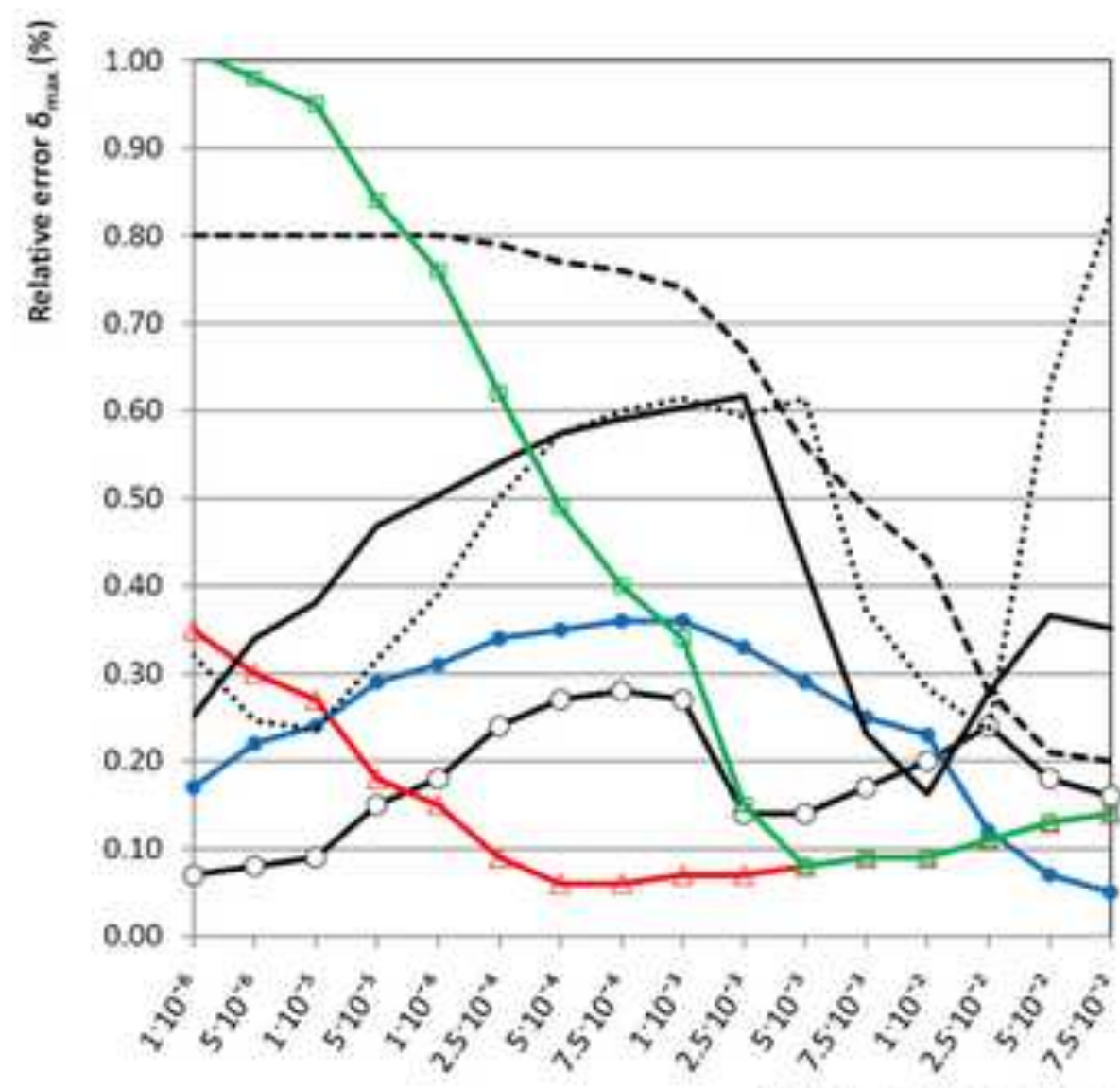

Relative roughness $(\varepsilon / D)$ $-\infty$ Barr (1981):

$\lambda=\left(-2 \cdot \log _{10}\left[(\varepsilon / D) / 3.7+\left(4.518-\log _{10}[\operatorname{Re} / 7]\right) /\left(\operatorname{Re} \cdot\left(1+\left[\operatorname{Re} e^{0.52} / 29\right) \cdot(\varepsilon / D)^{0.7}\right)\right)\right]\right)^{-2}$

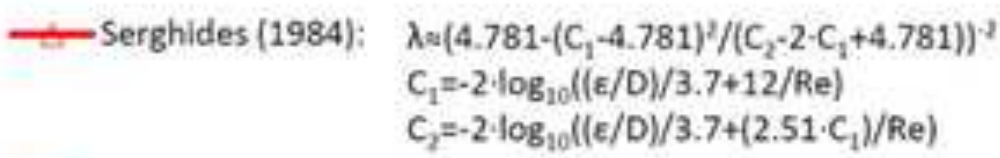

$\rightarrow$ Chen (1979):

$\lambda=\left(-2 \cdot \log _{10}[(\varepsilon / D) / 3.7065) \cdot(5.0452 / R e)\right.$.

$\left.\log _{10}\left[(1 / 2.8257),(\varepsilon / D)^{1.1098}+\left(5.8506 / \operatorname{Re}^{0.8381}\right)\right]\right)^{2}$

— Fang et al. (2011):

$\lambda=\left(1.613 \cdot \ln \left[0.234 \cdot(\varepsilon / D)^{1.1007}-60.525 / \operatorname{Re}^{1.1105}+56.291 / \operatorname{Re}^{1.0712}\right]\right)^{-2}$

--- Sonnad and Goudar (2006):

$\lambda=\left(0.8686 \cdot \ln \left[0.4587 \cdot \operatorname{Re} / \mathrm{S}^{5 / 5}+11\right]\right)^{2}$

$S=0.124 \cdot \operatorname{Re} \cdot(\varepsilon / D)+\ln (0.4587 \cdot \operatorname{Re})$

...... Papaevangelou et al. (2010):

$\left.\lambda=\left(0.2479-0.0000947 \cdot\left[7-\log _{10}(R e)\right]^{4}\right) /\left(\log _{10} t(\varepsilon / D) / 3.615+7.366 / \operatorname{Re}^{0914}\right]\right)^{2}$

-Zigrang and Sylvester (1982):

$\left.\lambda=\left(-2 \cdot \log _{10}\left[(\varepsilon / D) / 3.7-5.02 / \operatorname{Re}-\log _{10}[(\varepsilon / D) / 3.7+13 / \operatorname{Re}]\right]\right]\right)^{2}$ 
Ghanbariet al. (2011):

$$
\lambda \approx\left(-1.52 \cdot \log _{10}\left[((\varepsilon / D) / 7.21)^{1.042}+(2.731 / R e)^{0.9152}\right]\right)^{-2.169}
$$

Relative roughness: $\varepsilon / D$

$$
10^{-1}
$$

$$
\delta<2 \%
$$

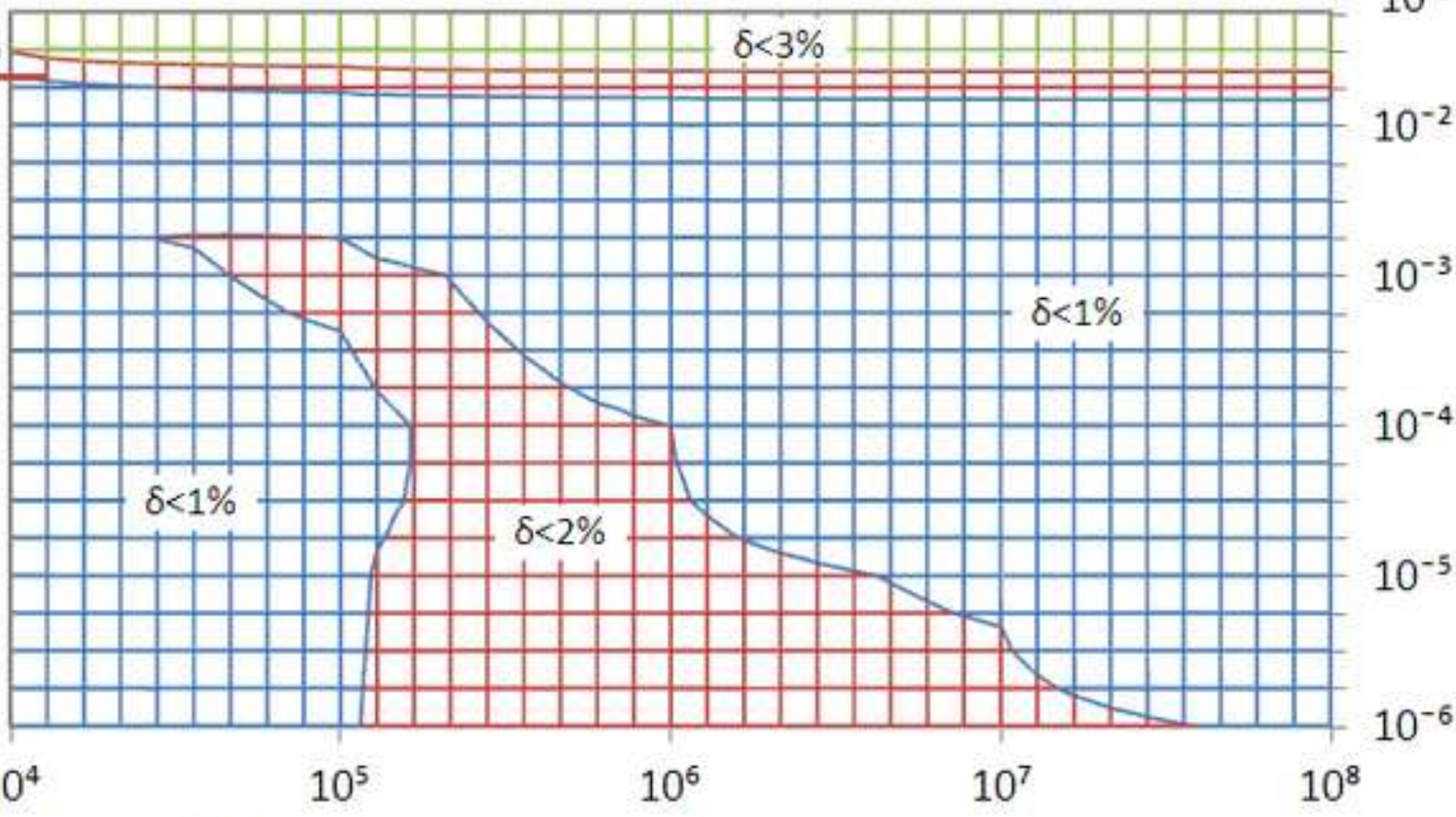

$\square 2-3 \%$

$\square 1-2 \%$

$\square 0-1 \%$

Reynolds number: Re 


\section{Here presented:}

$\lambda \approx\left(-2 \cdot \log _{10}\left[150.39 / \operatorname{Re}^{0.95865}-152.66 / \operatorname{Re}+(\varepsilon / D) / 3.71\right]\right)^{-2}$

$\lambda \approx\left(-2 \cdot \log _{10}\left[\left(1.25603 /\left[\operatorname{Re} \cdot\left[-0.0015702 / \ln (\operatorname{Re})+0.3942031 / \ln ^{2}(\operatorname{Re})+2.5341533 / \ln { }^{3}(\operatorname{Re})\right]^{0.5}\right]\right)+(\varepsilon / D) / 3.71\right]\right)^{-2}$

Relative roughness: $\varepsilon / D$

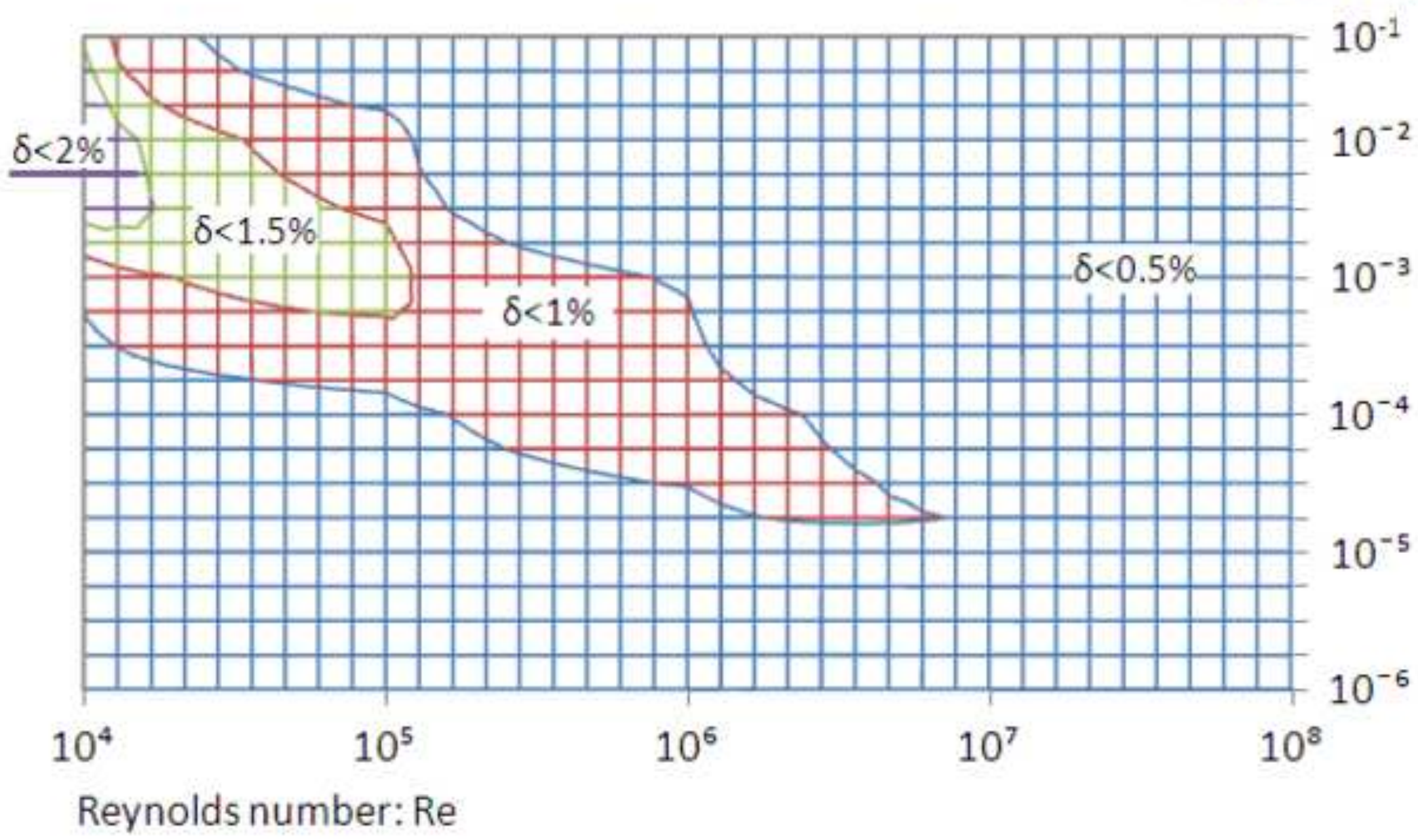




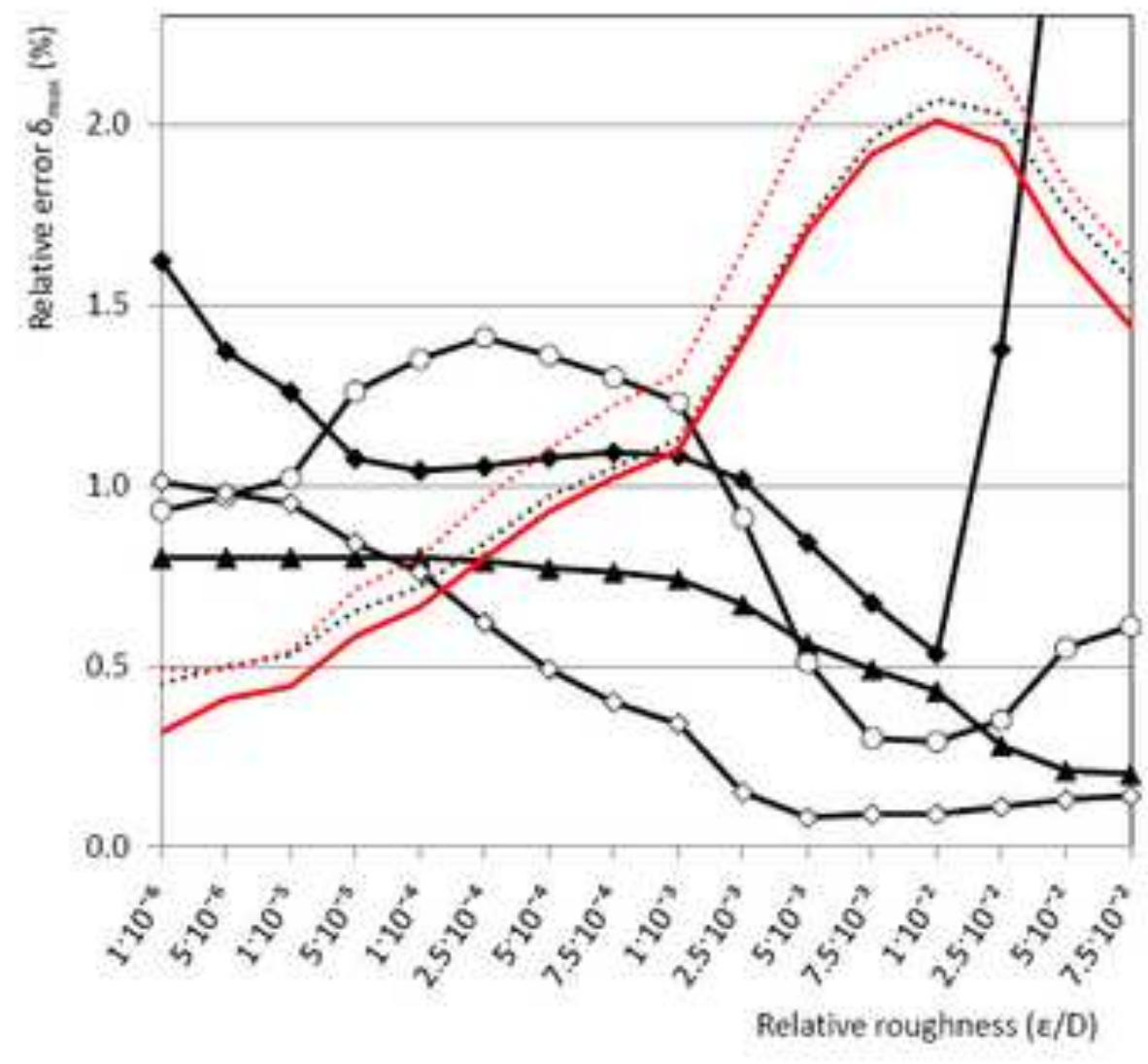

- Sonnad and Goudar [2006): $\lambda=\left(0.8686 \cdot \operatorname{in}\left[0.4587 \cdot \operatorname{Re} / S^{2 / 45+1]}\right]\right)^{2}$ $S=0.124 \cdot \operatorname{Re}-(\varepsilon / D)+\ln (0.4587 \cdot \operatorname{Re})$ - Haaland (1983):

$\lambda=\left(-1.8 \log _{u p}\left(6.9 / \operatorname{Re}+((\varepsilon / D) / 3.7)^{1.11}\right]\right)^{-2}$

- Zigrang and Sylvester (1982):

$\lambda=\left(-2 \cdot \log _{10}\left[(\varepsilon / D) / 3.7-5.02 / R_{e} \cdot \log _{10}[(\varepsilon / D) / 3.7+13 / R e l l]\right)^{2}\right.$

—-Ghanbari et al, (2011);

$\lambda=\left(-1.52 \cdot \log _{10}\left[((\varepsilon / D) / 7.21)^{2042}+(2.731 / \text { Re })^{0.9152}\right]\right)^{-2169}$

+.....Manadilit (1997):

$\lambda=\left(-2 \cdot \log _{10}\left(t(\mathrm{D}) / 3.7+95 / \mathrm{Re}^{0.963}, 96.82 / \mathrm{Re}\right)\right)^{2}$

,......Brkic (2011a):

$\left.\lambda=\left(-2 \cdot \log _{10}(\varepsilon / D) / 3.7+2.18 \cdot \beta / \operatorname{Re}\right]\right)^{-2}$

$B=\ln (\mathrm{Re} /[1.816 \cdot \ln (1.1 \cdot \operatorname{Re} / \ln [1+1.1 \cdot \operatorname{Re}])]$

new

$\lambda=\left(-2 \cdot \log _{40}\left[150.39 / \mathrm{Ae}^{0.9845}, 152.66 / \operatorname{Re}+(\varepsilon / \mathrm{D}) / 3.71\right]\right)^{\prime 2}$

$\lambda=\left\{-2-\log _{i} d(1.25603)\right.$

$\left.\left.\left./\left[\operatorname{Re} \cdot\left[-0.0015702 / \ln (\operatorname{Re})+0.3942031 / \mathrm{n}^{2}(\operatorname{Re})+2.5341533 / \mathrm{n}^{3}(\operatorname{Re})\right]^{5}\right]\right]+(\varepsilon / \mathrm{D}) / 3.71\right]\right)^{2}$ 


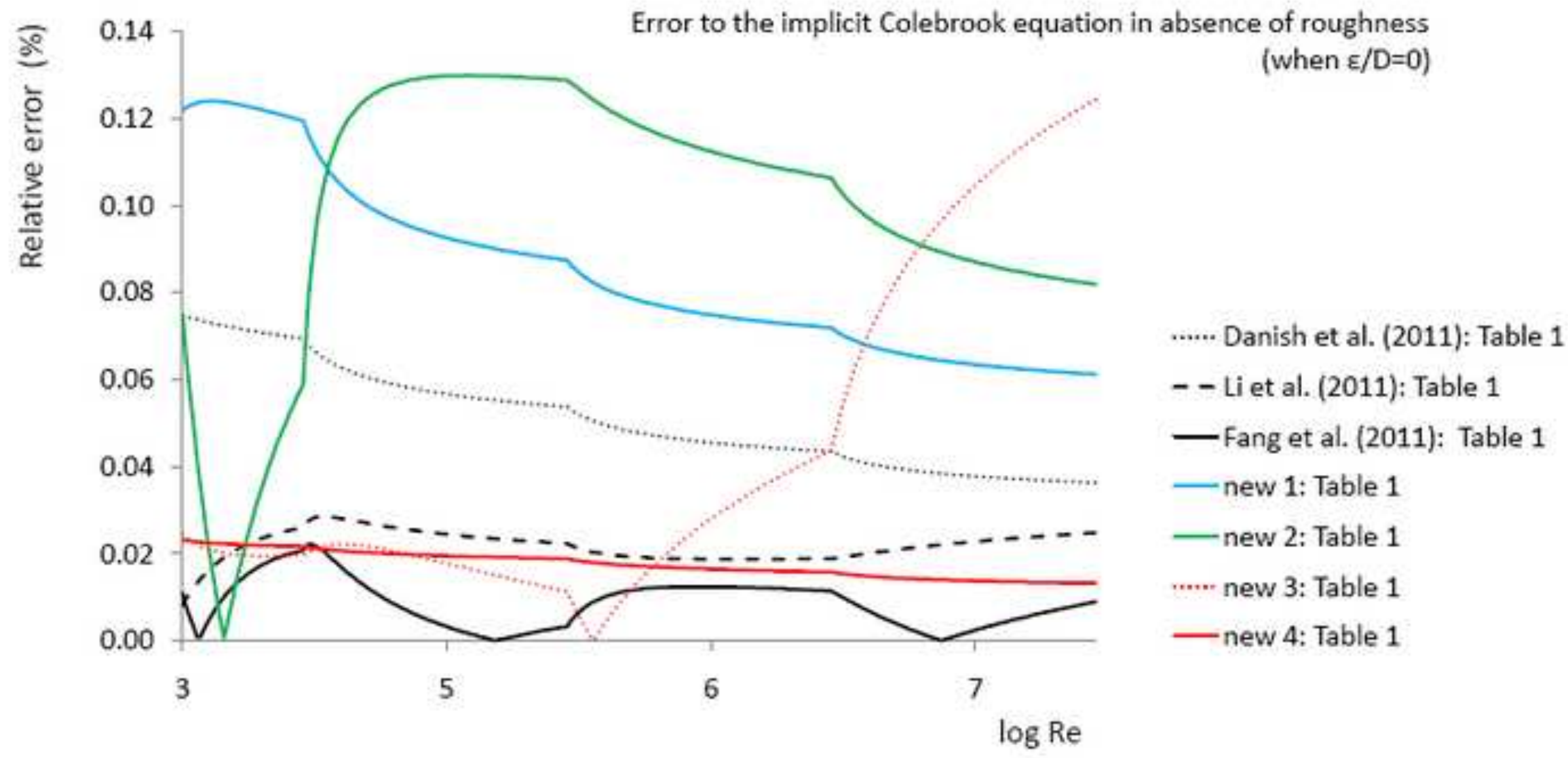


graphical abstract DB
Click here to download e-component: graph abstract DB.tif

if

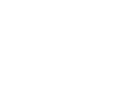

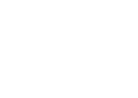

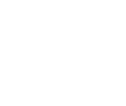

(2)

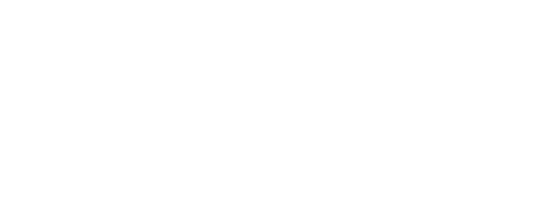

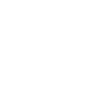

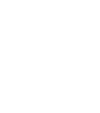

.

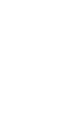

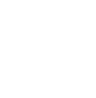

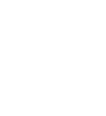

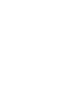

,
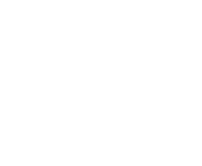
research highliglight DB
Click here to download e-component: Research highlights DB.doc

research highliglight DB
Click here to download e-component: Research highlights DB.doc

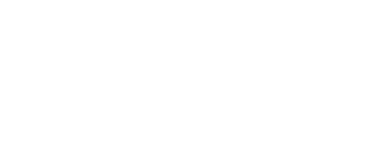

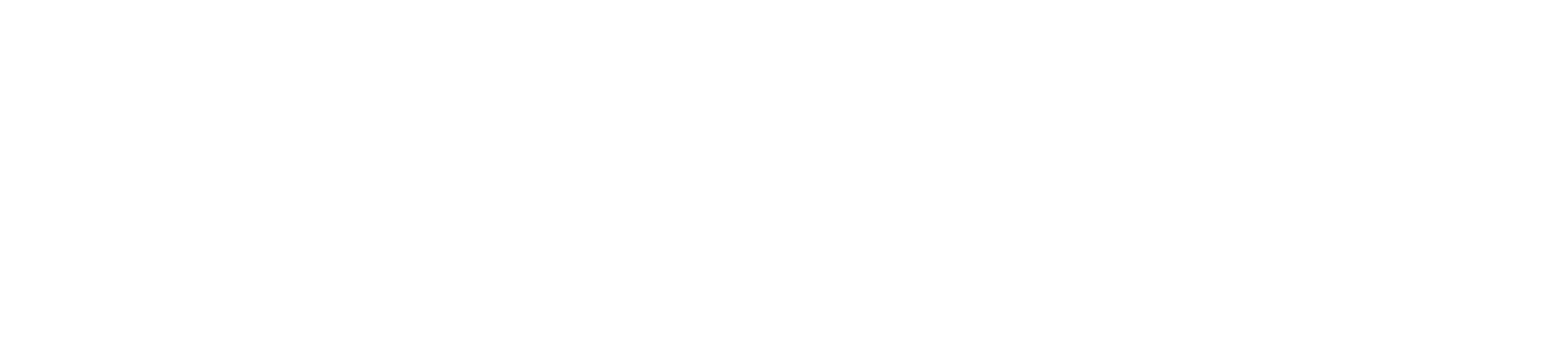

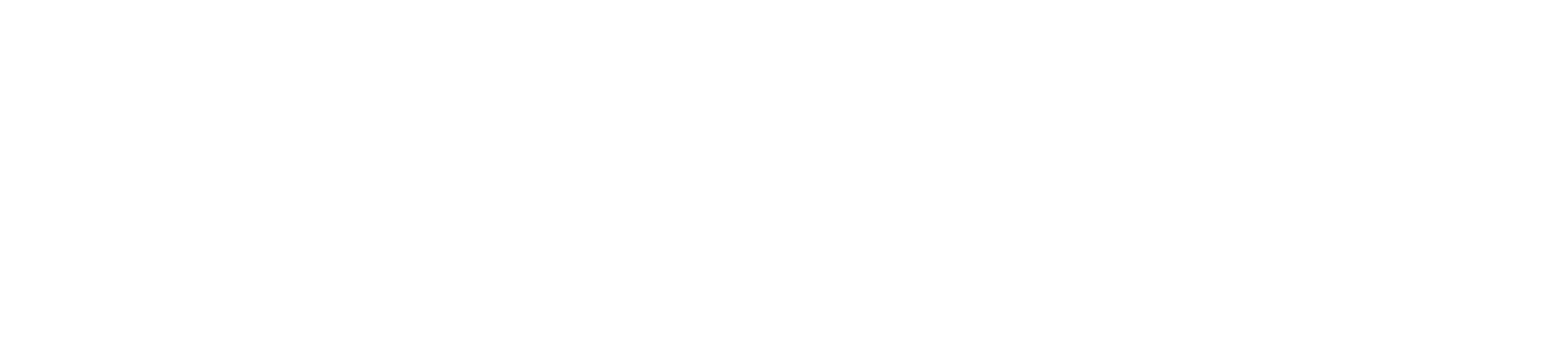

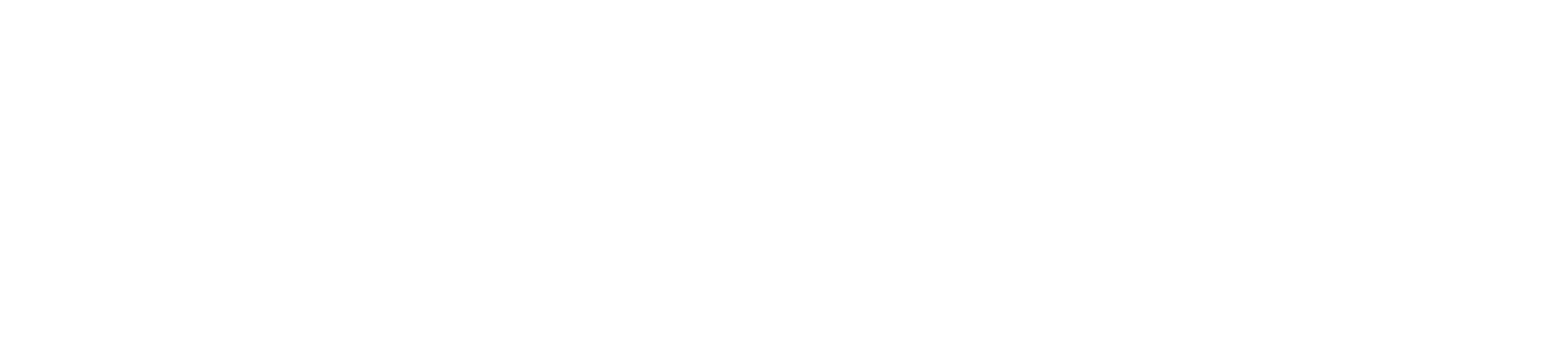

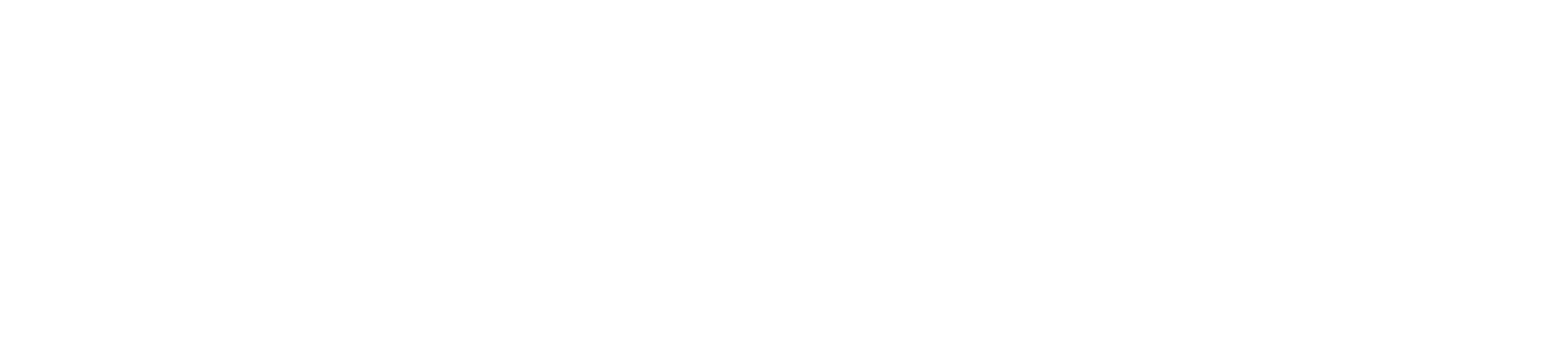

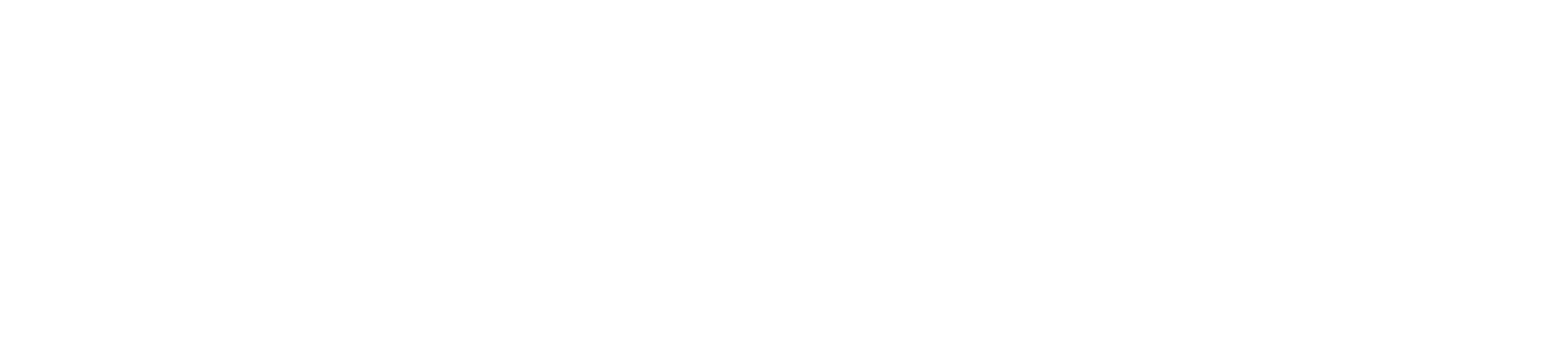

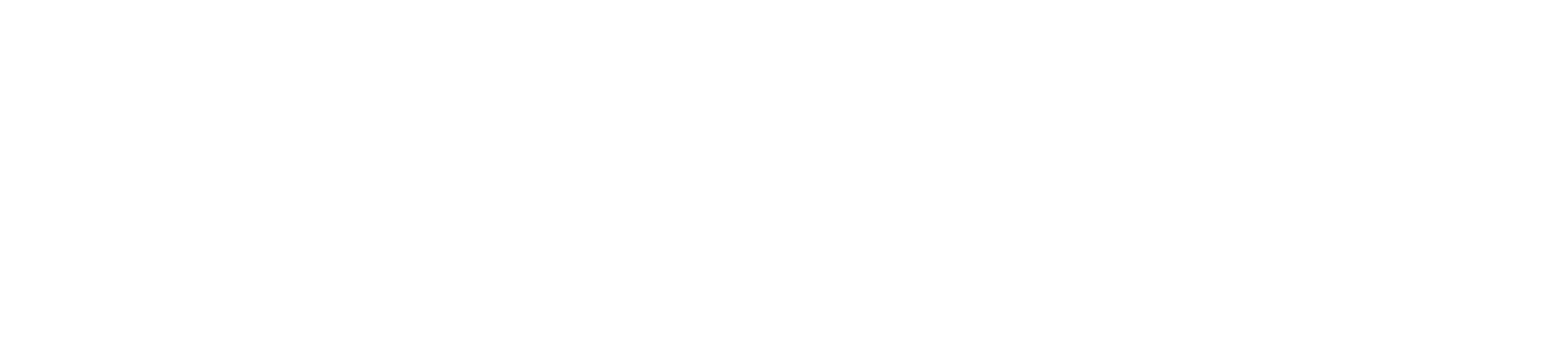

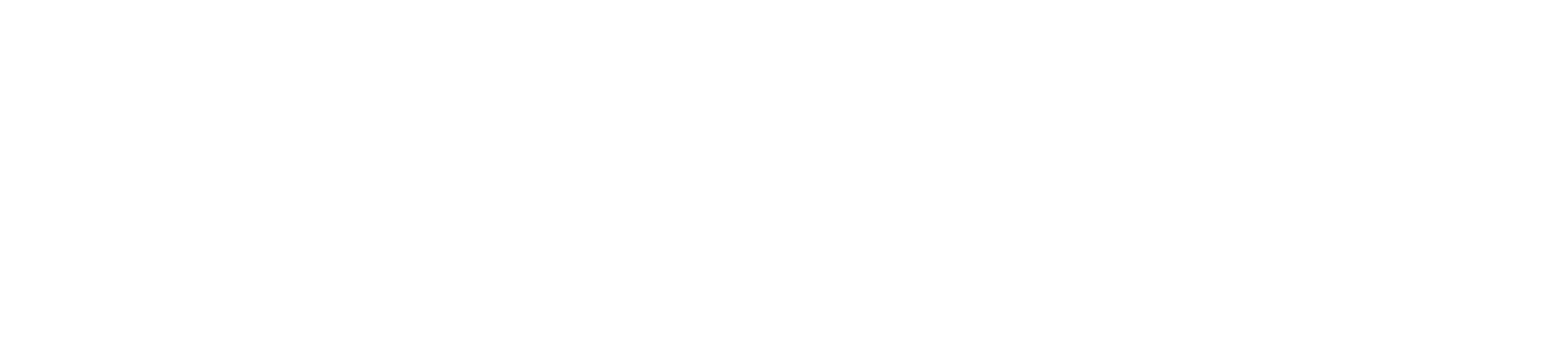

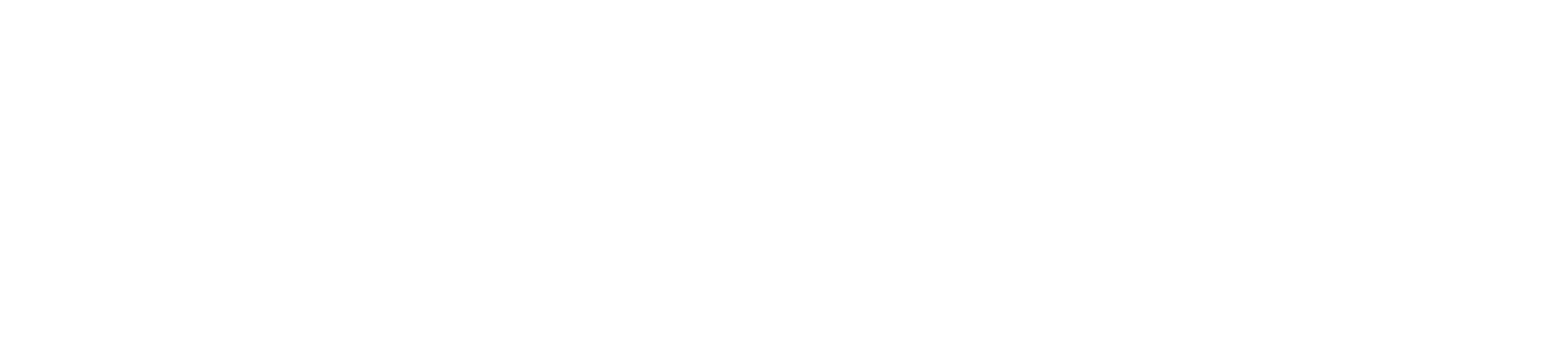

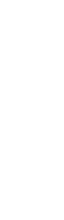

.

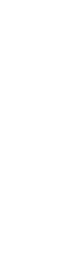

(1)

. 
Brkic
Click

Click here to download e-component: Brkic.JPG

Click here to download e-component: Brkic.JPG

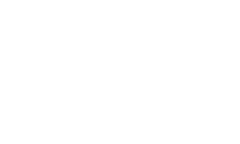

$\sqrt{2}$

(1)

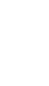

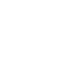
(1)

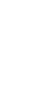

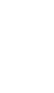

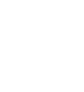
(1)

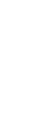

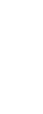
(1) (1) (1) (1)

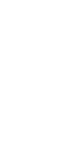
(1) (1) (1)

(1) 